\title{
Does collateral fuel moral hazard in banking?
}

\author{
J-P. Niinimäki \\ Helsinki School of Economics and HECER
}

Discussion Paper No. 231

September 2008

ISSN 1795-0562

HECER - Helsinki Center of Economic Research, P.O. Box 17 (Arkadiankatu 7), FI-00014 University of Helsinki, FINLAND, Tel +358-9-191-28780, Fax +358-9-191-28781,

E-mail info-hecer@helsinki.fi, Internet www.hecer.fi 


\section{Does collateral fuel moral hazard in banking?*}

\section{Abstract}

This paper presents two models in which the fluctuating value of loan collateral (real estate) generates the problem of moral hazard between a bank and a deposit insurance agent. The bank finances risky projects against collateral and relies on the rising collateral value. If the collateral value later appreciates, the bank enjoys handsome profits; otherwise, the bank fails. The findings are rather consistent with the characteristics of the topical subprime mortgage crisis.

JEL Classification: G21, G22, G28

Keywords: Banking Crises, Bank Regulation, Subprime Banking, Deposit Insurance, Moral Hazard,

J-P. Niinimäki

Department of Economics

Helsinki School of Economics

P.O. Box 1210

FI-00101 Helsinki

FINLAND

e-mail: juha-pekka.niinimaki@hse.fi

* The research has been supported by the Yrjö Jahnsson Foundation. This paper is forthcoming in Journal of Banking and Finance. 


\section{Introduction}

In the U.S.A numerous subprime banks are presently failing. Subprime banking represents a novel and rapidly growing segment of the mortgage market that channels loans to those borrowers, who fail to meet credit quality requirements in the standard mortgage market. This paper poses the question of whether banks, for example subprime banks, gamble with the future value of collateral (house property). Borrowers of the subprime banks are risky clients but their loans are secured by house property. Even when a borrower cannot earn sufficient income to repay the loan, the bank does not face a loan loss if the value of house property appreciates during the loan period so that it covers the loan repayment. More precisely, most borrowers are able to earn sufficient income to repay their loans and thus they can keep their houses. A few borrowers are unable to earn income, but the bank can seize the collateral (house property) and in this way extract the whole loan repayment. As a result, each loan yields the repayment and the bank makes handsome profits if the collateral value appreciates. If the value of the house property depreciates, the bank fails, since the defaulted loans yield low income to the bank due to the depreciated collateral value. Consequently, the banks are de facto gambling with the future value of house property.

According to the classic banking theory, collateral reduces bank risk. Even when a borrower has insufficient income to repay his loan, the bank can seize the collateral (Bester, 1985). This paper does not deny that collateral may reduce bank risk. Yet, the positive effects of collateral are challenged using two models, in which the fluctuating value of collateral generates the moral hazard problem between banks and the bank regulator. In Section 3, loans are secured by outside collateral. Its future value is uncertain, which tempts banks to gamble with the collateral. Banks refrain from the costly efforts of borrower evaluation, but lending decisions are based on the collateral. If the collateral value is high at a later date, the bank 
makes a profit. If the collateral value depreciates, the bank fails and the bank regulator, who runs the deposit insurance scheme, has to pay the costs of excessive risk taking. Section 4 models the example of a subprime bank. ${ }^{1}$ The moral hazard effect is shown to be strengthened when outside collateral is replaced with inside collateral, which is funded with the loan capital.

The paper is related to abundant research on moral hazard in banking and analysis on collateral. ${ }^{2}$ When Bester (1985) investigates how collateral affects the risk of a single loan, the question to be answered is: how does collateral influence bank risk at the aggregate level. Does collateral alleviate or worsen the bank's risk of failure? We are primarily interested in investigating the circumstances, if any, in which collateral can fuel the moral hazard effects of deposit insurance. As mentioned above, we are able to observe these circumstances. Our findings are rather consistent with existing empirical evidence which is surveyed in Section 2. Consequently, our paper proposes a theory which explains why banking crises are connected with fluctuations in real estate markets.

Section 2 reviews the empirical evidence. Section 3 examines how outside collateral may generate the moral hazard problem. Section 4 finds the same result using inside collateral, and Section 5 concludes.

\footnotetext{
${ }^{1}$ For details on subprime lending see Chomsisengphet and Pennington-Cross (2006).

${ }^{2}$ For moral hazard in banking see Matutes and Vives (2000), Blum (2002), Chiesa (2001), Niinimäki (2001), Repullo (2004), Decamps et al. (2004), Freixas et al. (2004), Jeitschko and Jeung (2005), Kopecky and VanHoose (2006), Lepetit et al. (2008), Kang and Liu (2008) as well as Nikitin and Smith (2008).
} 


\section{Empirical evidence}

This section surveys the empirical evidence on collateral and banking crises.

Observation 1. The ratio of collateral to loan size is high. According to Binks et al. (1993) and de Meza and Southey (1996), in the U.S.A the ratio of collateral to loan is, on average, 1:2 and in the Great Britain exceeds unity for $85 \%$ of loans.

Observation 2. A major portion of collateral consists of real estate. According to Borio's (1996) observations, the portion of loans secured by real estate collateral varies in different countries: $59 \%$ in Great Britain, $56 \%$ in Canada and $66 \%$ in United States.

Observation 3. Collateral value, particularly the value of real estate, fluctuates substantially. In Stockholm inflation-adjusted property prices rose rapidly in the late 1980s, rising to $450 \%$ of the level at the beginning of the decade. From 1989 to 1993, inflationadjusted property prices depreciated to less than the 1982 level (Herring and Wachter, 1999). In Japan, commercial property prices rose over 300\% during the 1980 s, but declined again to the initial level over the next five years (Hilbers et al., 2001).

Observation 4. Banking crises are commonly preceded by a depreciation in the value of real estate. Herring and Wachter (1999, p. 2), for instance, document the following:

\footnotetext{
"One striking feature of the current Asian financial crisis is that the most seriously affected countries first experienced a collapse in property prices and a consequent weakening of their banking systems before an exchange rate crisis."
}

Zhu's (2003) empirical study focuses on the level of banking profitability and loan loss provisions during the upswing and downward phases of real estate markets. On average, bank profits were almost halved, and loan loss provisions nearly doubled when the value of real estate depreciates. In the FDIC 's extensive empirical analysis on the Savings and Loan Crisis, 
Hanc (1998. p. 19-24) offers the following conclusions: "Commercial and real estate markets in particular deserve attention because boom and bust activity in these markets was one of the main causes of losses at both failed and surviving banks."

Observation 5. There is abundant evidence to suggest that lending decisions are often based on collateral and that this lending method leads to crises. As to the Savings and Loan Crisis in U.S.A, Freund et al. (1998, p. 155) document:

\footnotetext{
"Traditionally, decisions to extend loans that are collateralized by commercial real estate property are evaluated by lenders primarily on the borrowers' ability to generate earnings from the investment sufficient to cover the existing debt payments. This is a fundamental tenet of the lending function. As a backup source of security, lenders evaluate the worth of investment property as potential collateral to cover the loan value in the case of default by the borrower. Starting in the late 1970s and continuing for the most of the following decade, examiners observed that lenders loosened loan terms relating to debtservice coverage and placed relatively more emphasis on the value of the collateral in making funding decisions. This change in loan procedures was based primarily on the assumption that real estate values (collateral values) would continue to rise in the future as they had in the recent past. .... When the real estate markets collapsed starting in the late 1980s, many lenders discovered that collateral values were often insufficient to cover existing loan losses".
}

Hilbers et al. (2001, p. 14) underline that before the banking crises in Finland and Sweden "lending decisions relied primary on availability of collateral rather than cash flow evaluations." As regards to the Asian crisis, Collyns and Senhadji (2005, p. 112) document: “Typically, techniques for credit assessment by banks were weakly developed, and banks tended to rely heavily on property collateral (and, to some extent, equity collateral) in making loan decisions." The banking crisis in Japan was preceded by similar lending policy. Herring and Wachter (1999, p.40) report: "Some banks apparently tended to rely on the rising value of land rather than rigorous credit analysis in underwriting loans." 


\section{Outside collateral}

\subsection{Economy}

Consider a risk-neutral economy with banks, borrowers (= entrepreneurs ) and a bank regulator. Banks and entrepreneurs maximize their expected returns whereas the regulator runs a deposit insurance scheme and supervises banks. ${ }^{3}$ Each entrepreneur can undertake an investment project, which requires a unit of input capital. Since an entrepreneur has no capital of his own, he needs to seek financing from a bank. Bank size is 1 and it has no capital of its own. The bank funds its lending by attracting deposits at the interest rate of the economy, $r$. As is common in this type of model, it is assumed that the regulator cannot directly observe bank risk. He can, however, observe loan collateral as well as the loan interest rates and he knows the characteristics of the economy. As a result, he can anticipate accurately whether the economic environment is such that the moral hazard problem appears or does not appear.

The economy has two types of entrepreneurs: good and bad. The project of a good entrepreneur - a good project - succeeds with probability $\mu_{G}$ producing $Y$ units. The project of a bad entrepreneur - a bad project - succeeds with probability $\mu_{B}$ producing $Y$ units. If unsuccessful, the projects produce no output. In the economy, the share of good entrepreneurs is $g$, and the rest of the entrepreneurs, $1-g$, are bad. On average a loan succeeds with probability

$s=g \mu_{G}+(1-g) \mu_{B}$.

\footnotetext{
${ }^{3}$ Deposits are insured in order to eliminate bank runs (see Niinimäki, 2003).
} 
It is assumed that an average project is unprofitable

$s Y<r$.

As a result, a loan to an unknown borrower is unprofitable. Unfortunately, the type of an entrepreneur is unobservable to outsiders. Only banks can separate good and bad entrepreneurs by monitoring them. Monitoring incurs non-monetary costs $m$ and it is assumed to be socially valuable. More precisely, the following assumption is made

$\mu_{G} Y>r+\frac{m}{g}$

This and (2) together provide

$m<(1-g)\left(r-\mu_{B} Y\right)$.

It is necessary to detail (3) and (4). Let us begin from (4). Since $m>0$, bad projects have negative NPV, $\mu_{B} Y<r$. No loan should be granted to bad entrepreneurs. In addition, (4) informs that the costs of monitoring a loan applicant are smaller than the social costs of the bad project. Let us now turn to (3). A monitoring bank contacts loan applicants until the measure of contacted good entrepreneurs is 1 and finances their projects. Before that, the bank has faced $1 / \mathrm{g}$ loan applicants. Hence, the total costs of monitoring amount to $\mathrm{m} / \mathrm{g}$. Given (3), the NPV of a good project covers the costs of monitoring and the loan interest rate. It is socially optimal to monitor loan applicants, separate good and bad entrepreneurs and finance the projects of good entrepreneurs. 
The task of monitoring is delegated to banks that operate under limited liability. Unfortunately, since monitoring incurs costs and since it is unobservable to outsiders, banks have the temptation to neglect it. This generates the problem of moral hazard between banks and the regulator. The banks maximize their expected profits and exert effort in monitoring only if it is at least as profitable as the non-monitoring strategy.

In the first best arrangement, the entrepreneur type (good or bad) would be observable and the hidden information problem could be avoided. This alternative is unachievable in the model. In the second best arrangement, the entrepreneurs are separated using bank monitoring. Monitoring incurs costs but the most devastating arrangement, investment with bad projects, is avoided. If the bank's choice of action (monitoring, nonmonitoring) were contractible, the loans would be monitored by banks. Yet, monitoring is assumed to be unobservable and it is not possible to commit to a contract that forces banks to monitor. Banks need to be motivated to monitor. For brevity, few assumptions are made.

\section{Assumption 1. A monitoring bank is risk free.}

In addition, a monitoring bank makes zero profits because of perfect competition. This makes it easy to examine moral hazard. A bank neglects monitoring if the non-monitoring strategy yields some degree of profit to it.

According to banking theory, collateral can be used to screen loan applicants (e.g. Bester, 1985). In more complicated models, the probability of project success depends on the amount of collateral and the monitoring activity. In this paper, the role of collateral is strongly simplified. Collateral is needed in the model, of course, since the effects of collateral are explored. In addition, to explore the moral hazard effects of deposit insurance, banks have an active monitoring role. It would be possible to investigate the moral hazard effects of 
collateral by constructing a model in which the role of collateral is more detailed. Yet, for simplification the role of the collateral is modelled in an elementary way; collateral affects only the loan interest rate. This simple role is sufficient to show that in some cases collateral fuels moral hazard. ${ }^{4}$

More precisely, borrowers (=entrepreneurs) can influence the loan interest rate by pledging $C$ units outside collateral that consists of real estate in the bank's neighbourhood. The initial amount of collateral is assumed to be fixed at the beginning of the period; that is, each borrower pledges the same amount of collateral, $C$. The future value of collateral at the end of the period is uncertain. With probability $h$, the collateral value appreciates during the loan period and it is $\bar{\alpha} C$ units at the end the period. With probability $1-h$ the collateral value depreciates and is $\underline{\alpha} C$ units at the end of the period, $\underline{\alpha}<1<\bar{\alpha}$. Thus, the expected value of collateral, $C^{E}$, is

$$
C^{E}=[h \bar{\alpha}+(1-h) \underline{\alpha}] C .
$$

In addition, the initial value of collateral, $C$, is equal to its expected value, $C^{E}$. Therefore, collateral is priced correctly.

\footnotetext{
${ }^{4}$ In the following, the initial amount of collateral is fixed. It is possible to assume that this fixed amount of collateral is determined by a rule that is not modelled. For example, even a good entrepreneur will take the loan capital and run with it if the loan is not secured by outside collateral. Suppose that this "take the money and run" option creates private benefits $B$ to a borrower. When the borrower pledges outside collateral so that $C=B$, the run is unprofitable. If the borrower runs, he loses the collateral. Hence, the initial amount of collateral is determined by the "take the money and run option". In the following we examine how this amount of collateral affects moral hazard in banking.
} 
The shares of good and bad borrowers, $g$ and $1-g$, are known in the economy and in the bank's portfolio of customers. A certain share of the financed good projects, $\mu_{G}$, and bad projects, $\mu_{B}$, is successful both in the economy and in a loan portfolio. Thus, only the future value of collateral is uncertain. Finally, we make the following assumption

Assumption 2. The bank's income from collateral is, at a maximum, equivalent to the loan repayment.

Section 3 presents a model in which moral hazard is avoided in the absence of outside collateral but when the loans are secured by outside collateral, the moral hazard problem may appear. It may be a bit puzzling that adding risk mitigation (here in the form of collateral) should increase the volatility of loan returns! How can adding insurance to a loan make the loan riskier? To see this, note that the bank's income consists of two elements

i. Successful loans yield loan repayments

ii. Unsuccessful loans yield collateral

Thanks to perfect diversification, the future share of successful loans in the bank's loan portfolio is certain. Hence, the bank's income from successful loans (i.) is also (almost) certain. On the other hand, when the future value of collateral fluctuates, the bank's collateral proceeds from unsuccessful loans (ii.) are risky. If this effect is sufficiently strong, the introduction of collateral may accelerate the volatility of bank returns. Due to the accelerated volatility, the moral hazard behaviour may be profitable. By investing in monitoring, the bank earns zero returns due to perfect competition. Without monitoring, the bank avoids the costs of monitoring, but the future share of successful loans is relatively small. Yet, if the collateral value appreciates during the loan period, the unsuccessful loans yield relatively high collateral proceeds, thereby making the bank profitable. If the collateral value depreciates, the bank fails. 
Since the expected returns from the non-monitoring strategy are positive to the bank, it optimally neglects monitoring and the moral hazard problem is present.

Again, we aim to show that the introduction of collateral may generate the problem of moral hazard. ${ }^{5}$ To show this, we explore three scenarios: 1.) Bank returns with monitoring; 2.) Bank returns without collateral and without monitoring; 3.) Bank returns with collateral and without monitoring. Thanks to perfect competition, scenario 1 yields zero returns. This is shown in subsection 3.2. Subsection 3.3 investigates banking without monitoring. First, it is demonstrated that a non-monitoring bank fails in the absence of loan collateral. Thus, moral hazard is avoided in the absence of collateral (scenario 1 is more profitable than scenario 2). Then we indicate that a non-monitoring bank may earn positive expected returns when the loans are secured by collateral (scenario 3 is more profitable than scenario 1). The moral hazard problem appears.

\subsection{Bank returns under monitoring}

Since the banking sector is perfectly competitive, the loan interest rate is at a level that yields zero returns to the bank that exerts effort in monitoring

$$
\mu_{G} R+\left(1-\mu_{G}\right) h \operatorname{Min}[\bar{\alpha} C, R]+\left(1-\mu_{G}\right)(1-h) \underline{\alpha} C=r+\frac{m}{g} .
$$

\footnotetext{
${ }^{5}$ Fundamentally, the deposit insurance option creates the moral hazard problem. Since collateral is now the one and only instrument of risk taking, we stress the effects of collateral by stating that collateral fuels moral hazard.
} 
The L.H.S indicates the expected bank income whereas the costs of banking are on the R.H.S. On the L.H.S $\mu_{G} R$ describes the loan interest income from successful loans. Since the share of successful loans is certain, the loan interest income is also certain. The second term shows the bank's collateral proceeds from unsuccessful loans when the collateral value appreciates during the loan period. If $\bar{\alpha} C>R$, the collateral value exceeds the loan repayment and the unsuccessful loans also yield the entire repayment, $R$, to the bank. A borrower can keep the surplus, $\bar{\alpha} C-R>0$. If $\bar{\alpha} C<R$, the collateral value does not cover the loan repayment and the bank can seize the entire collateral. The third term in (6) displays the bank's collateral proceeds from unsuccessful loans when the collateral value depreciates during the loan period. It is known that $\underline{\alpha} C<R{ }^{6}$ The R.H.S reveals that the income is used to pay interest on deposits and to cover the costs of monitoring. Depending on whether $\bar{\alpha} C<R$ or $\bar{\alpha} C>R$, two alternative loan interest rates can be solved from (6)

$$
\begin{gathered}
R=\frac{r+\frac{m}{g}-\left(1-\mu_{G}\right) C}{\mu_{G}}, \text { when } \bar{\alpha} C<R . \\
R=\frac{r+\frac{m}{g}-\left(1-\mu_{G}\right)(1-h) \underline{\alpha} C}{\mu_{G}+\left(1-\mu_{G}\right) h}, \text { when } \bar{\alpha} C \geq R .
\end{gathered}
$$

Both loan interest rates are declining in collateral. Borrowers are willing to pledge collateral only if it reduces the loan interest rates. To simplify the model, we make the following assumption that is based on Assumption 1.

Assumption 1'. $\mu_{G} R+\left(1-\mu_{G}\right) \underline{\alpha} C>r$, which makes a monitoring bank risk free.

\footnotetext{
${ }^{6}$ If $\underline{\alpha} C \geq r$, the participation constraint of bad borrowers is not satisfied (see Lemma 2).
} 
Assumption 1' together with (6) and (7) ensures that a monitoring bank earns zero returns. A bank neglects monitoring if the non-monitoring strategy yields positive expected returns for it.

\subsection{Bank returns in the absence of monitoring}

Consider a representative bank that neglects monitoring. The bank charges the very same interest on loans as the monitoring banks. Thus, the loan interest rate does not reveal the nonmonitoring strategy. Since the bank does not monitor loan applicants, it finances their projects in the order of appearance. As a result, the borrowers consist of good and bad entrepreneurs. Their shares are $g$ and $1-g$. Since a certain share of good projects and bad projects succeed, the future share of successful loans is also certain, $s=g \mu_{G}+(1-g) \mu_{B}$.

We aim to show that the fluctuating value of collateral may cause the moral hazard problem. To begin, we show that moral hazard is avoided in the absence of collateral.

Lemma 1. When borrowers pledge no collateral, a bank fails if it neglects monitoring. The moral hazard problem is avoided.

Proof. Without monitoring, the bank returns are $s R(0)-r$. Inserting $R(0)$ from (7.i) into $s R(0)-r$ provides $m-(1-g)\left[r-\mu_{B} R(0)\right]<m-(1-g)\left(r-\mu_{B} Y\right)<0$. Q.E.D

The intuition is obvious. Given the law of large numbers, the bank has $g \mu_{G}$ successful loans that are allocated to good entrepreneurs. The loans yield total profit $m$. The rest of the loans, $1-g$, are channelled to bad entrepreneurs and they yield total loss $(1-g)\left[r-\mu_{B} R(0)\right]$. 
Since monitoring has positive social value, recall (4), the losses from bad borrowers exceed the profits from good borrowers and the bank fails.

Next we will show that moral hazard may appear when the loans are secured by collateral. Two scenarios occur depending on the volatility of the collateral value. We will first explore scenario $\bar{\alpha} C<R$ and then scenario $\bar{\alpha} C \geq R$.

\subsubsection{Case $\bar{\alpha} C<R$}

This subsection reveals that the non-monitoring strategy may be profitable when $\bar{\alpha} C<R$ (more precisely $C<(r+m / g) /\left[\bar{\alpha} \mu_{G}+\left(1-\mu_{G}\right)\right]$ ). The inequality means that even when the collateral value appreciates during the loan period, the appreciation is so moderate that the collateral value does not cover the loan repayment. If a borrower cannot repay his loan, the bank can seize the entire collateral.

Bad entrepreneurs seek a bank loan only if their participation constraint is satisfied. The following Lemma is derived in Appendix A.

Lemma 2. There exists such a screening level of collateral, $C_{\text {Screen } 1}$, that bad borrowers will not seek a bank loan if $C>C_{\text {Screen1 }}, C_{\text {Screen } 1}=\mu_{B}\left(\mu_{G} Y-r-m / g\right) /\left(\mu_{G}-\mu_{B}\right)$.

Thus, when the initial amount of collateral exceeds $C_{\text {Screen1 }}$, only good entrepreneurs seek a loan. In the following, we assume that borrowers do not have sufficient collateral. That is, the analysis focuses on cases $C \in\left[0, C_{\text {Screen } 1}\right]$. As a result, a bad entrepreneur optimally seeks a loan, because it is profitable for him 
$\mu_{B}[Y-R(C)]-\left(1-\mu_{B}\right) C>0$.

The non-monitoring strategy is unprofitable when the collateral value is certain.

Lemma 3. If the collateral value is certain, a non-monitoring bank fails.

Proof: The bank earns $s R(C)+(1-s) C-r$. Inserting $R(C)$ from (7.i) into this provides

$$
m+(1-g)\left[\mu_{B} Y-r\right]-(1-g)\left[\mu_{B}(Y-R)-\left(1-\mu_{B}\right) C\right] .
$$

Given (4), the sum of the first two terms is negative. Given (8), the third term is negative. Hence, (9) is negative and the bank fails. Q.E.D

So far we have observed that moral hazard is avoided without collateral (Lemma 1) and when the collateral value is certain (Lemma 3). It is time to show that moral hazard may appear when the future value of collateral is uncertain. The initial amount of collateral satisfies $C \in\left[0, C_{\text {Screen } 1}\right]$ and the expected bank returns amount to

$$
\pi_{B}(C)=h \operatorname{Max}[s R(C)+(1-s) \bar{\alpha} C-r, 0]+(1-h) \operatorname{Max}[s R(C)+(1-s) \underline{\alpha} C-r, 0] .
$$

Here the limited liability option is expressed in detail: bank returns cannot be negative. The first term describes bank returns when the collateral value appreciates during the loan period and the second term represents the bank returns when the collateral value depreciates during the loan period. Note that the shares of successful and unsuccessful loans are certain, $s$ and $1-s$. Given Lemma 3 and $\underline{\alpha} C<C$, the second term is zero. Thus, (10) can be expressed as 


$$
\pi_{B}(C)=h \operatorname{Max}[s(R-r)+(1-s)(\bar{\alpha} C-r), 0] .
$$

It is known that $R(C)>r$ ( see (7.i)). When $\bar{\alpha} C \geq r$, the collateral proceeds from unsuccessful loans also cover the costs of banking. Thus, at least when $\bar{\alpha} C \geq r$, (11) is positive. The bank profits when the collateral value appreciates. Hence, the expected profits from the non-monitoring strategy are positive. Since the monitoring strategy yields zero returns, the bank optimally neglects monitoring. The moral hazard problem appears.

It is necessary to find out exactly when moral hazard appears. Substituting $R(C)$ from (7.i) into (11) provides rewritten expected bank returns

$$
\pi_{B}(C)=\frac{-(1-g) r\left(\mu_{G}-\mu_{B}\right)+\frac{s m}{g}+\left[(1-g)\left(\mu_{G}-\mu_{B}\right)+(\bar{\alpha}-1)(1-s) \mu_{G}\right] C}{\mu_{G}} .
$$

It is possible to see three facts: i.) The non-monitoring strategy is unprofitable without collateral (Lemma 1); ii.) The returns from the non-monitoring strategy are increasing in collateral (see (12)); iii.) When the volatility of the collateral value is sufficient, $\bar{\alpha} C_{\text {Screen } 1} \geq r$, the non-monitoring strategy is profitable (recall (11)). Given i. - iii., when $\bar{\alpha} C_{\text {Screen } 1} \geq r$, there is always such a minimum amount of collateral, $C_{\text {Min }}<C_{\text {Screen } 1}$, that the bank returns are zero, $\pi_{B}\left(C_{\text {Min }}\right)=0$. Even when the volatility of the collateral value is smaller, $\bar{\alpha} C_{\text {Screen } 1}<r$, it may be possible to have such a minimum amount of collateral, $C_{\text {Min }} \leq C_{\text {Screen } 1}$, that the bank returns are zero, $\pi_{B}\left(C_{\text {Min }}\right)=0$ (see (11)). Only if $\pi_{B}\left(C_{\text {Screen } 1}\right)<0$, the volatility of the collateral value is so small that the non-monitoring strategy is unprofitable. A conclusion follows. 
Lemma 4. When the volatility of the collateral value is sufficient, there exists such a minimum amount of collateral, $C_{\text {Min }}$, that expected bank returns are zero without monitoring, $\pi_{B}\left(C_{\text {Min }}\right)=0$. If the initial amount of collateral is small, $C \leq C_{\text {Min }}$, moral hazard is avoided. If the initial amount of collateral is at the middle level, $C_{\text {Min }}<C \leq C_{\text {Screen } 1}$, moral hazard appears. If the initial amount of collateral is large, $C>C_{\text {Screen } 1}$, moral hazard is avoided, because the participation constraint of bad entrepreneurs is not satisfied. When the volatility of the collateral value is insufficient, the non-monitoring strategy is unprofitable at each level of collateral, $\pi_{B}\left(C_{\text {Screen } 1}\right)<0$.

Consequently, the moral hazard problem may appear if the initial amount of collateral is large enough and if the volatility of the collateral value is sufficient. Then, the future value of collateral, $\bar{\alpha} C$, can be so high that even the defaulted loans yield relatively high collateral proceeds to the bank, thereby making the bank returns positive.

So far the amount of collateral has been fixed. Suppose that it can be decided by the bank. Given (12), the bank returns are increasing in C. Under constraint $\bar{\alpha} C<R(C)$, the returns are maximized when $\bar{\alpha} C$ approaches towards $R(C)$ without limit, $\bar{\alpha} C \approx R(C)$. Given $\bar{\alpha} C \approx R(C)$ and (7.i), it is possible to solve the optimal amount of collateral.

Lemma 5. If a bank can choose the amount of collateral, the optimal amount is $\bar{\alpha} C^{*}=$ $R\left(C^{*}\right)$ or $C^{*}=(r+m / g) /\left[\bar{\alpha} \mu_{G}+\left(1-\mu_{G}\right)\right]$, when the participation constraint is satisfied, $C^{*} \leq C_{\text {Sreen } 1}$. If $C^{*}>C_{\text {Sreen } 1}$, the optimal amount of collateral is $C_{\text {Sreen } 1}$. 


\subsubsection{Case $\bar{\alpha} C \geq R$}

This subsection indicates that the non-monitoring strategy is profitable with certainty when $\bar{\alpha} C \geq R$. When the collateral value appreciates, it is so high, $\bar{\alpha} C$, that it covers the total loan interest payment, $R$. As a result, the bank receives the loan repayment, $R$, even when the financed project fails, whereas the borrower can keep surplus, $\bar{\alpha} C-R$.

Again, if the collateral requirement is large, the participation constraint of bad entrepreneurs is not satisfied. The following lemma is derived in Appendix B.

Lemma 6. When $\bar{\alpha} C \geq R(C)$, there is such a screening level of collateral, $C_{\text {Screen } 2}$, that bad entrepreneurs will not borrow if $C>C_{\text {Screen } 2}$, where

$$
C_{\text {Screen } 2}=\frac{\left[\mu_{G}+\left(1-\mu_{G}\right) h\right] \mu_{B} Y-\left(r+\frac{m}{g}\right)\left[\mu_{B}+\left(1-\mu_{B}\right) h\right]}{(1-h) \underline{\alpha}\left(\mu_{G}-\mu_{B}\right)} .
$$

Therefore, if each entrepreneur has more than $C_{\text {Screen } 2}$ units of collateral, it is possible to screen bad borrowers from the loan market. We assume that borrowers have less collateral, $C \in\left[0, C_{\text {Screen } 2}\right]$. The collateral value fluctuates and the expected bank returns are

$$
h \operatorname{Max}[s R+(1-s) \operatorname{Min}(\bar{\alpha} C, R)-r, 0]+(1-h) \operatorname{Max}[s R+(1-s) \underline{\alpha} C-r, 0] .
$$

The first term reveals bank returns when the future value of collateral is high and the second term indicates the same when the collateral value is low. The second term is zero: the bank 
fails when the collateral value depreciates (Lemma 3 and $\underline{\alpha} C<C$ ). Given $\operatorname{Min}(\bar{\alpha} C, R)=R>r$, the expected bank returns can be restated as $h[R(C)-r]>0$. The non-monitoring strategy is profitable and the moral hazard problem appears.

Lemma 7. When $\bar{\alpha} C \geq R(C)$, the moral hazard problem is always present if the participation constraint of bad entrepreneurs is satisfied, $C \leq C_{\text {Screen } 2}$.

Finally, suppose that the bank can decide the initial amount of collateral. What is the optimal amount? Inserting the loan interest rate from (7.ii) into $R(C)-r>0$ provides bank returns

$$
\frac{\left(1-\mu_{G}\right)(1-h)(r-\underline{\alpha} C)+\frac{m}{g}}{\mu_{G}+\left(1-\mu_{G}\right) h},
$$

which are decreasing in $C$. The bank optimally reduces the amount of collateral to the lower limit $\bar{\alpha} C=R(C)$. Therefore, the optimal amount of collateral is the same as in the case $\bar{\alpha} C<R(C)$ and is expressed in Lemma 5. This section can be summed up as follows.

Proposition 1. Suppose that the initial amount of outside collateral satisfies the participation constraint of bad borrowers. If the collateral value can appreciate sufficiently ( at least when $\bar{\alpha} C \geq r$ ), the moral hazard problem is present. A bank optimally grants loans against collateral without monitoring loan applicants and relies on the rising collateral value. If the future value of collateral is high, unsuccessful loans yield high collateral proceeds for the bank, which enjoys profits. If not, the bank fails. 
According to Proposition 1, the banking sector is profitable if the collateral value appreciates, but if it depreciates, a banking crisis occurs.

Collateral requirements can be utilized to eliminate moral hazard. Given Lemma 4, moral hazard appears only if the initial amount of collateral is at the middle level. If loan applicants possess plenty of collateral, the regulator can stipulate banks to lend only against a sufficient amount of collateral so that bad entrepreneurs can be screened from the loan market (Lemmas 2 and 6). If the amount of collateral is very large, loans are risk-free. Unfortunately, it is unlikely that loan applicants have sufficient collateral. Then, the regulator might follow an opposite strategy by setting an upper limit to collateral so that banks can not gamble with it (Lemma 4, $C \leq C_{\text {Min }}$ ). However, this is impossible when collateral is needed to control borrowers (footnote 4). Therefore, it is possible that moral hazard cannot be eliminated.

In this section, we have solved the unique equilibrium loan interest rate for monitoring banks under the competitive assumption of zero expected profits, $R$. Thereafter, we have explored a representative non-monitoring bank that charges the very same interest on loans as monitoring banks, and demonstrated that the non-monitoring bank enjoys positive expected profits in the specific economic environment (at least when $\bar{\alpha} C \geq r$ ). In equilibrium, all banks behave identically and neglect monitoring. As a result, the original loan interest rate, $R$, cannot persist in equilibrium. All banks will become non-monitoring banks and the equilibrium loan interest rate will drop below $R$ owing to perfect competition. However, it is known from (2) that an average project is unproductive without monitoring. As a result, banking cannot be profitable because deposit insurance is priced correctly (recall that under monitoring the deposit insurance premium is zero since banks are risk-free). A rational regulator anticipates correctly that in the specific economic environment all banks would neglect monitoring and the regulator should bear the costs of the gamble. Hence, the regulator cannot grant banking licenses at all. The moral hazard problem is so severe that no banks can 
be established. Banks can be established only when the volatility of the collateral value is so low that the moral hazard problem does not appear.

Corollary 1. When the economic environment is such that the moral hazard problem is present, no banks can be established.

\subsection{Discussion}

In Diamond (1984), a bank operates as a delegated monitor. The moral hazard problem between the bank and its depositors is avoided since the number of borrowers is huge and the risks and returns of their projects are independent. Thanks to the law of large numbers, the loan portfolio is perfectly diversified. Thus, depositors can rely on the bank being safe.

This section follows the vision of Diamond (1984). Thanks to the law of large numbers, the share of successful loans is certain. In the absence of monitoring, the share of successful loans is so small that the bank fails. Thus, in the absence of collateral the bank is motivated to monitor borrowers and it is risk-free because bad borrowers are screened out. Collateral offers another potential screening mechanism because, if set high enough, bad borrowers would not participate in the loan market. However, collateral may also induce moral hazard behaviour. Since the value of collateral is the same, low or high, collateral offers the bank a correlated risk with which it can gamble. When the future value of collateral is sufficiently high, $\bar{\alpha} C \geq R$, it is insignificant for the bank whether or not a borrower is able to earn income and thereby repay his loan. In both cases the bank receives the same payment, $\bar{\alpha} C=R$. The future value of collateral is crucial. If it is high, the bank enjoys handsome profits, but if it is low, the bank fails. 


\section{Inside collateral}

\subsection{Economy}

In section 3, collateral consisted of outside collateral. Outside collateral refers to cases where the borrower pledges assets not used in the project. In this section collateral consists of inside collateral, which is funded with loan capital. Since this type of collateral incurs no costs to the borrower, his participation constraint is satisfied. The findings of this section are similar to the findings of the previous section.

Inside collateral, which is funded with loan capital, is common in mortgage lending. To emphasize this, the model is updated somewhat. Consider a homebuyer who has no capital of his own and seeks for a bank loan. The loan size is 1 unit and it is used at the beginning of the period to purchase a house, which is pledged as collateral, $C=1$ unit. The value of the house fluctuates during the loan period. More precisely, at the beginning of the period, the value is $C=1$ units, but at the end of the period it is either $\bar{\alpha} C$ units (with probability $h$ ) or $\underline{\alpha} C$ units (with probability $1-h$ ), $\underline{\alpha}<1<\bar{\alpha}$. Again, the current value of the house is equal to its expected value. Banks maintain no equity capital and they fund loans by attracting deposits at the interest rate of the economy, $r$. The bank size is 1 and the banking sector is assumed to be perfectly competitive.

The economy has two types of homebuyers: good and bad. With probability $\mu_{G}$, a good homebuyer can earn income $Y$, but with probability $1-\mu_{G}$ he earns nothing. A bad homebuyer can earn $Y$ with probability $\mu_{B}$, whereas with probability $1-\mu_{B}$ he in unable to earn anything, $\mu_{G}>\mu_{B}$. The share of good homebuyers is $g$, while the rest of the 
homebuyers, $1-g$, are bad. Thus, an average homebuyer succeeds to earn $Y$ with probability $s=g \mu_{G}+(1-g) \mu_{B}$. A loan to an average homebuyer is assumed to be unprofitable

$s Y+C<r$

where $C=1$. That is, the expected earnings of an homebuyer, $s Y$, and the expected value of his house property at the end of the period, $C$, do not cover the interest rate of the economy, $r$. A loan to a good homebuyer is assumed to have clearly positive NPV

$\mu_{G} Y+C>r+\frac{m}{g}$.

Now (16) and (17) together provide

$m<(1-g)\left(r-\mu_{B} Y-C\right)$.

In addition, it is assumed that

$Y>r+\frac{m}{g}$

It is possible to detail (17)-(19) as follows. The type of a homebuyer is private information and thus unobservable to outsiders. Only banks can separate good and bad homebuyers by monitoring them. Monitoring incurs a nonmonetary cost, $m$, to the bank. A monitoring bank meets loan applicants until the measure of contacted good homebuyers is 1 . Before that the 
bank needs to contact $1 / \mathrm{g}$ loan applicants. Thus, the total costs of monitoring amount to $\mathrm{m} / \mathrm{g}$ and the costs of a loan add up to $r+m / g$. Now (19) ensures that a homebuyer (good or bad) who succeeds in earning income $Y$ is able to repay his loan and thus keep his house. According to (18), no loan should be granted to a bad homebuyer. The relatively large share of bad homebuyers and the negative NPV of their loans induce so severe expected losses to lenders that it is socially productive to monitor loan applicants in order to separate good and bad homebuyers. That is, the non-monetary costs of monitoring a loan applicant, $m$ units, is smaller than the expected losses from a bad project, $(1-g)\left(r-\mu_{B} Y-C\right)$. Besides, (17) indicates that a loan to a good homebuyer is clearly profitable. The good homebuyer's expected wealth covers both the interest rate and the costs of monitoring. The task of monitoring is delegated to banks. To investigate moral hazard, it is necessary to examine bank returns under monitoring (subsection 4.2) and in the absence of monitoring (subsection 4.3).

\subsection{Bank returns with monitoring}

Although the economy is different than in Section 3, the models are almost identical. The loan interest rate, for example, can again be solved from (6). Additionally, (7) displays the loan interest rates, whereas Assumption 1' ensures that a monitoring bank is risk-free and enjoys zero returns. Two main differences to Section 3 exist. First, since loans are secured by inside collateral, which is purchased with loan capital, the borrowers' participation constraints are relaxed. Second, the initial amount of collateral is now fixed, $C=1$. Since the monitoring strategy yields zero returns, the bank neglects monitoring, if this strategy is profitable. 


\subsection{Bank returns without monitoring}

Assume that a representative bank neglects monitoring. The decision is unobservable to the regulator. The bank charges interest $R$ on loans so that the loan interest rate is the same as under monitoring and it does not reveal the non-monitoring strategy. The bank grants loans to applicants in the order of appearance. Thanks to the law of large numbers, the shares of good and bad homebuyers in the loan portfolio are the same as in the economy, $g$ and $1-g$. The expected bank returns are the same as under outside collateral

$$
\pi_{B}(C)=h \operatorname{Max}[s R+(1-s) \operatorname{Min}(\bar{\alpha} C, R)-r, 0]+(1-h) \operatorname{Max}[s R(C)+(1-s) \underline{\alpha} C-r, 0] .
$$

The first term expresses the returns under the high collateral value and the second term shows the returns when the collateral value becomes low. We obtain the following result.

Lemma 8. If the collateral value is certain, the moral hazard problem disappears.

Proof. When $\bar{\alpha}=\underline{\alpha}=1$, (20) simplifies to $m-(1-g)\left(r-\mu_{B} R-1+\mu_{B}\right)$. Given (18) this is negative and thus the non-monitoring strategy is unprofitable. Q.E.D

Assume now that the collateral value fluctuates. The second term in (20) is zero (Lemma 8 and $\bar{\alpha}<1)$. Consider the first term. Two scenarios occur depending on whether $\bar{\alpha} C<R$ or $\bar{\alpha} C \geq R$. When $\bar{\alpha} C<R$, (20) can be rewritten as $s(R-r)+(1-s)(\bar{\alpha} C-r)>0$. The first part is positive, but the second part may be negative. At least when $\bar{\alpha} C \geq r$, (20) is positive but it can be positive even when $\bar{\alpha} C<r$. When $\bar{\alpha} C \geq R$, (20) simplifies to $R>r$ which is always true. A conclusion follows. 
Proposition 2. With inside collateral that is funded with the loan capital, the moral hazard problem arises, if the collateral value may appreciate sufficiently (at least when $\bar{\alpha} \geq r$ ).

Assume that the value of house property (=collateral) appreciates. Then, unsuccessful loans also yield relatively high income to the bank. If $\bar{\alpha} \geq r$, the collateral value is so high that the bank is profitable. Most of all, if $\bar{\alpha} \geq R$, the collateral value is so high that each loan yields the whole loan repayment, $R$, to the bank. Now $s$ homebuyers are able to earn income, repay their loans and thus keep their houses. The rest of the homebuyers are unable to earn income, but the value of their house property has appreciated considerably during the loan period. The house property, collateral, can be seized and liquidated by the bank. Since $\bar{\alpha} \geq R$, the bank obtains the promised loan repayment, $R$, in total whereas each borrower can keep surplus, $\bar{\alpha}-R$. Since every loan yields the same repayment, $R$, to the bank, the share of successful loans, $s$, is rather insignificant for the bank. The appreciated value of collateral is crucial.

Consider now scenario $\bar{\alpha}>R$. It is optimal for a bad entrepreneur to seek for a bank loan even when $\mu_{B}=0$. Although the borrower cannot earn income and thus repay the loan, he can keep surplus $\bar{\alpha}-R>0$ if the collateral value appreciates. It is easy to see that the moral hazard problem is relatively likely to appear with inside collateral.

Lemma 9. The moral hazard problem is more likely to appear with inside collateral than with outside collateral.

Proof: When $C=1$, the moral hazard problem appears if $s(R-r)+(1-s)[\operatorname{Min}(\bar{\alpha}, R)-r]>0$ under both forms of collateral. With inside collateral, there are no participation constraints. 
With outside collateral the participation constraint may eliminate the case $C=1$. Thus, moral hazard is a more severe problem under the terms of inside collateral. Q.E.D

Similar to Section 3, we have investigated a representative non-monitoring bank which charges the very same interest on loans as monitoring banks, and demonstrated that the bank may optimally neglect monitoring. In equilibrium all banks behave identically and neglect monitoring. Thanks to perfect competition, the loan interest rate will drop below $R$. However, we know from (16) that banking is unprofitable in the absence of monitoring when the deposit insurance is priced correctly. Thus, the regulator - who rationally anticipates that in the existing economic environment each bank would neglect monitoring - cannot grant banking licenses at all. The moral hazard problem is so severe that no banks can be established. The result is identical to Corollary 1.

\section{Conclusions}

This paper reviews scenarios in which collateral is used as a risk-taking instrument. A bank refrains from the costly efforts of borrower evaluation, but lending decisions are based on the collateral. If the collateral value is high later, the bank enjoys handsome profits because unsuccessful loans yield high collateral proceeds. If the collateral value is low, the bank fails because the collateral proceeds from unsuccessful loans are low. Consequently, banks are willing to finance unproductive projects based on the assumption that collateral values would later appreciate. This type of problem is most likely to appear when the collateral consists of inside collateral which is funded with the loan capital. 


\section{Appendix A: Lemma 2}

Without collateral the expected returns of a bad borrower are $\mu_{B}(Y-R(0))$. Given (7.i), this is positive. With collateral, the returns are $\mu_{B}(Y-R(C))-\left(1-\mu_{B}\right) C$. Inserting the loan interest rate from (7.i) into this gives $\mu_{B} Y-\left[\mu_{B} r+\mu_{B} m / g+C\left(\mu_{G}-\mu_{B}\right)\right] / \mu_{G}$. We denote this by $\Psi$. It is easy to see that $\Psi$ is decreasing in $C$. With full collateral, $R=r+m / g$, $\Psi$ simplifies to $\mu_{B} Y-(r+m / g)$, which is negative. Thus, such a screening amount of collateral, $C_{\text {Sreen } 1}, 0<C_{\text {Screen } 1}<r+m / g$, exists that bad borrowers earn zero returns. Q.E.D

\section{Appendix B: Lemma 6}

When $\bar{\alpha} C \geq R(C)$, the expected returns of a bad borrower are $\pi_{B}(C)=\mu_{B}[Y-R(C)]+$ $\left(1-\mu_{B}\right) h[\bar{\alpha} C-R(C)]-\left(1-\mu_{B}\right) C$. The returns are positive when $C$ is sufficiently small (however, $\bar{\alpha} C \geq R(C)$ ). Inserting loan interest rate from (7.ii) into $\pi_{B}(C)$ gives

$$
\frac{\left[\mu_{G}+\left(1-\mu_{G}\right) h\right] \mu_{B} Y-\left(r+\frac{m}{g}\right)\left[\mu_{B}+\left(1-\mu_{B}\right) h\right]-(1-h) \underline{\alpha}\left(\mu_{G}-\mu_{B}\right) C}{\mu_{G}+\left(1-\mu_{G}\right) h} .
$$

(B.1) is decreasing in $C$ and negative when $\underline{\alpha} C \geq r$. There is $C$ such that (B.1) is 0. Q.E.D 


\section{References}

Bester, H., 1985. Screening vs. rationing in credit markets with imperfect information. American Economic Review 57, 850-855.

Binks, M., Ennew, C., Reed, G., 1993. Small Businesses and their Banks. Forum of Private Business, Knutsford.

Blum, J., 2002. Subordinated debt, market discipline, and bank's risk taking. Journal of Banking and Finance 26(7), 1427-1441.

Borio, C., 1996. Credit Characteristics and the Monetary Policy Transmission Mechanism in Fourteen Industrial Countries: Facts, Conjectures and Some Econometric Evidence. In: Alders, K., Koedijk, K., Kool, C., Winder, C. (Eds.), Monetary Policy in a Converging Europe. Kluwer Academic Publishers: Boston.

Chiesa, G., 2001. Incentive-based lending capacity, competition, and regulation in banking. Journal of Financial Intermediation 10(1), 28-53.

Chomsisengphet, A., Pennington-Cross, A., 2006. The evolution of the subprime mortgage market. Federal Reserve Bank of St. Louis Review 88(1), 31-56.

Collyns, C., Senhadji, A., 2005. Lending Booms, Real Estate Bubbles, and the Asian Crisis. In: Hunter, W., Kaufman, G., Pomerleano, M. (Eds.), Asset Price Bubbles. The MIT Press: London.

Decamps, J.-P., Rochet, J.-C., Roger, B., 2004. The three pillars of Basel II: Optimizing the mix. Journal of Financial Intermediation 13, 132-155.

de Meza, D., Southey, C., 1996. The borrower's curse: Optimism, finance and entrepreneurship. Economic Journal 106, 375-386.

Diamond, D., 1984. Financial intermediation and delegated monitoring. Review of Economic Studies 51(3), 393-414. 
Freixas, X., Parigi, B., Rochet, J.-C., 2004. The lender of last resort: A twenty-first century approach. Journal of European Economic Association 2(6), 1085-1115.

Freund, J., Curry, T., Hirch, P., Kelly, T., 1998. Commercial Real Estate and the Banking Crises of the 1980s and Early 1990s. In: Hanc, G. (Eds.), History of the Eighties - Lessons for the Future, FDIC.

Hanc, G., 1998. The Banking Crises of the 1980s and Early 1990s: Summary and Implications. In: Hanc, G. (Eds.), History of the Eighties - Lessons for the Future, FDIC.

Herring, R., Wachter, S., 1999. Real estate booms and banking busts: An international perspective. Working paper No. 99-27, Wharton School Center for Financial Institutions, University of Pennsylvania.

Hilbers, P., Lei, Q., Zacho, L., 2001. Real estate market developments and financial sector soundness. Working paper No. 01/129, IMF.

Jeitschko, T., Jeung, S., 2005. Incentives for risk-raking in banking - a unified approach. Journal of Banking and Finance 29(3), 759-777.

Kang, J.-L., Liu, W.-L., 2008. Bank incentives and suboptimal lending decisions: Evidence from the valuation effect of bank loan announcements in Japan. Journal of Banking and Finance 32(6), 915-929.

Kopecky, K., VanHoose, D., 2006. Capital regulation, heterogeneous monitoring costs, and aggregate loan quality. Journal of Banking and Finance 30(8), 2235-2255.

Lepetit, L., Nys, E., Rous, P., Tarazi, A., 2008. Bank income structure and risk: An empirical analysis of European banks. Journal of Banking and Finance 32(1), 1452-1467.

Matutes, C., Vives, X., 2000. Imperfect competition, risk taking, and regulation in banking. European Economic Review 44(1), 1-34. 
Niinimäki, J.-P., 2001. Intertemporal diversification in financial intermediation. Journal of Banking and Finance 25(5), 965-991.

Niinimäki, J.-P., 2003. Maturity transformation without maturity mismatch and bank panics. Journal of Institutional and Theoretical Economics 159(3), 511-522.

Nikitin, M., Smith, T., 2008. Information acquisition, coordination, and fundamentals in a financial crisis. Journal of Banking and Finance 32(6), 907-914.

Repullo, R., 2004. Capital requirements, market power, and risk-taking in banking. Journal of Financial Intermediation 13(2), 156-182.

Zhu, H., 2003. The importance of property markets for monetary policy and financial stability. BIS Papers No. 219. 